\title{
Enhanced Detection of Emotional Facial Expressions in Borderline Personality Disorder
}

\author{
Lars Schulze $^{\mathrm{a}-\mathrm{c}}$ Gregor Domes $^{\mathrm{d}}$ Dürken Köppen ${ }^{\mathrm{e}}$ Sabine C. Herpertz ${ }^{f}$ \\ a Department of Educational Sciences and Psychology and ' ${ }^{\circ}$ Cluster of Excellence 'Languages of Emotion', \\ Freie Universität Berlin, 'Department of Psychiatry, Charité-Universitätsmedizin Berlin, Campus Benjamin Franklin, \\ Berlin, ${ }^{d}$ Department of Psychology, University of Freiburg, Freiburg, ${ }^{e}$ Hospital for Psychiatry, Psychotherapy and \\ Psychosomatics, Röbel, and fDepartment of General Psychiatry, University of Heidelberg, Heidelberg, Germany
}

\section{Key Words}

Borderline personality disorder $\cdot$ Emotion recognition •

Faces $\cdot$ Labeling $\cdot$ Sensitivity

\begin{abstract}
Background: Borderline personality disorder (BPD) is commonly proposed to be characterized by an enhanced sensitivity for emotional stimuli. In the present study, we investigated whether BPD patients show a superior detection of emotional facial expressions relative to healthy controls. The detection of emotional information in the environment represents an important facet of emotional sensitivity. Sampling and Methods: Twenty patients with BPD were compared with 25 healthy controls. The participants were presented a rapid, continuous stream of neutral and randomly inserted emotional facial expressions and were asked to report the presentation of an emotional facial stimulus after each trial. Availability of cognitive resources was manipulated via two different task demands. Results: The participants with BPD performed significantly better in the detection of positive and negative facial expressions compared to the healthy controls. False alarm rates did not differ significantly between the two groups. Conclusions: The BPD participants
\end{abstract}

showed an enhanced detection of emotional expressions that might be related to the emotional disturbances they experience. In particular, we will discuss the role of this superior emotion detection (in combination with previously reported deficits in the labeling of emotional states) for the understanding of emotional instability in BPD.

Copyright $\odot 2012$ S. Karger AG, Basel

\section{Introduction}

Borderline personality disorder (BPD) is a severe mental disorder which affects approximately $2 \%$ of the general population in western societies [1,2], with emotional instability being the most frequent and stable diagnostic criterion [3-5]. Thus, emotional instability is widely accepted to be 'at the core of borderline pathology' [6, p. 372] and was additionally shown to be directly related to many aspects of BPD psychopathology such as self-injurious behavior $[7,8]$, interpersonal problems, identity disturbances or feelings of chronic emptiness $[9,10]$.

Theoretical conceptualizations of BPD proposed three factors to underlie emotional instability: enhanced emotional sensitivity, stronger emotional responding and im-

\section{KARGER}

Fax +4161306 1234

E-Mail karger@karger.ch

www.karger.com
(C) 2012 S. Karger AG, Basel

0254-4962/13/0464-0217\$38.00/0

Accessible online at:

www.karger.com/psp
Lars Schulze

Department of Clinical Psychology and Psychotherapy

Freie Universität Berlin, Habelschwerdter Allee 45

DE-14195 Berlin (Germany)

Tel. +49 308385 6446, E-Mail lars.schulze@fu-berlin.de 
pairments in the ability to regulate negative emotions [11]. Studies available up to now provided evidence for more extreme emotional reactivity [12-16] as well as for deficits in the cognitive regulation of aversive emotions $[17,18]$. With regard to emotional sensitivity, first experimental results by Frank and Hoffman [19] reinforced clinical observations that suggested BPD patients perceive emotional states in others more accurately [20]. Follow-up studies, in contrast, demonstrated either unaltered recognition of emotional states [21-23] or impairments in the accurate perception of emotions [24-29]. It needs to be stated that two studies also reported enhanced emotion recognition capabilities in BPD [30, 31]; however, subsequent studies using similar paradigms failed to replicate these results $[21,28,32]$. Impairments in the recognition of emotions were particularly evident when patients with BPD had to integrate facial and prosodic information [33], or were required to rapidly discriminate facial expressions [34]. Thus, in contrast to initial assumptions, most studies in BPD suggest decreased accuracy in the recognition of emotions. These alterations in the recognition and perception of social signals, along with biases to evaluate others more negatively and aggressively $[35,36]$ and a tendency to perceive facial expressions as more negative [21, $37,38]$, might contribute to disturbances of the patients in social interactions [for review, see 39].

However, as illustrated by the preceding paragraph, the majority of studies investigated only one specific aspect of emotional sensitivity in BPD, i.e. emotion recognition. Findings regarding other aspects of emotional sensitivity, such as the detection of emotional information, for instance, are to date severely lacking [40]. Importantly, abnormalities in the detection of emotions were previously shown to be strongly related to emotional instability [for a review, see 41]. For instance, initial work by MacLeod et al. [42] illustrated experimentally induced biases in the detection of emotions to enhance the vulnerability of the participants for anxiety and negative mood, thereby supporting claims that sensitivity to emotional expressions represents an important aspect of emotional instability.

Consequently, in the present study we investigated a different facet of emotion sensitivity in BPD patients, i.e. emotion detection. In particular, we aimed to assess whether patients with BPD are characterized by a heightened detection of emotional facial expressions as predicted by theoretical models of BPD [11]. To this end, the participants were presented a rapid, continuous stream of neutral and randomly inserted emotional facial stimuli, while being asked to report the presence of an emotional stimulus after each trial. In addition, we aimed to explore the effects of the availability of cognitive resources on the detection of emotional stimuli by manipulating task demands.

\section{Methods}

Participants

Twenty-five healthy controls and 20 patients with a diagnosis of BPD were enrolled in the study. The healthy controls were recruited via public advertisements. The patients with BPD were recruited from two inpatient treatment facilities. All the patients were on a waiting list prior to treatment and none of them was admitted for acute psychiatric care. Only female participants were recruited to rule out possible effects of gender on the recognition of emotional stimuli [43] as well as differences in clinical symptoms between male and female patients with BPD [44].

All the participants underwent diagnostic screening with the Structured Clinical Interview for DSM-IV and the International Personality Disorder Examination [45]. All diagnostic interviews were conducted by a trained and clinically experienced psychiatrist (D.K.). Healthy controls were included if they had no current or lifetime diagnosis of mental or neurological disorders and did not take any psychotropic medication. BPD patients were excluded if they had comorbid diagnoses of psychotic disorders, bipolar affective disorders or had a neurological disease. Patients were required to be free of psychotropic medication for at least 2 weeks.

Participants were additionally screened regarding their intellectual abilities as assessed by a short version of the Wechsler Adult Intelligence Scale. The severity of BPD symptoms was assessed by a German version of the Zanarini Rating Scale for BPD [46] and the Borderline Symptom List-23 [47]. In addition, participants completed the Brief Symptom Inventory [48] and the Beck Depression Inventory [49]. Demographic and clinical characteristics of BPD patients and healthy controls are presented in table 1 .

The study design was approved by the ethics committee of the University of Rostock. All participants provided written informed consent after the procedures had been fully explained.

\section{Experimental Design}

The participants were presented a rapid, continuous stream of facial stimuli without interstimulus interval. Each trial lasted 1,750 $\mathrm{ms}$ and contained 15 stimuli presented for approximately $117 \mathrm{~ms}$. Within each trial, a picture of flowers or mushrooms was presented (labeled T1 in the following) that appeared equally often in positions 2-7 of the trial sequence. In addition, some trials contained an emotional (angry or happy) facial stimulus that was always presented after the appearance of $\mathrm{T} 1$. The remaining stimuli were neutral facial expressions (see fig. 1). Facial stimuli were selected from a standardized set of photographs, Karolinska directed emotional faces [50], and balanced with regard to gender (half female and half male portraits). All pictures were converted to gray scales and an oval vignette was used to hide hair and ears of facial stimuli.

The participants followed two task instructions. In single-task trials, the participants were asked to ignore T1 and to report the appearance of an emotional facial stimulus at the end of each trial. They were not required to indicate the specific valence of the perceived emotion. Rather, they were only asked to confirm or deny the presentation of an emotional stimulus in the preceding 


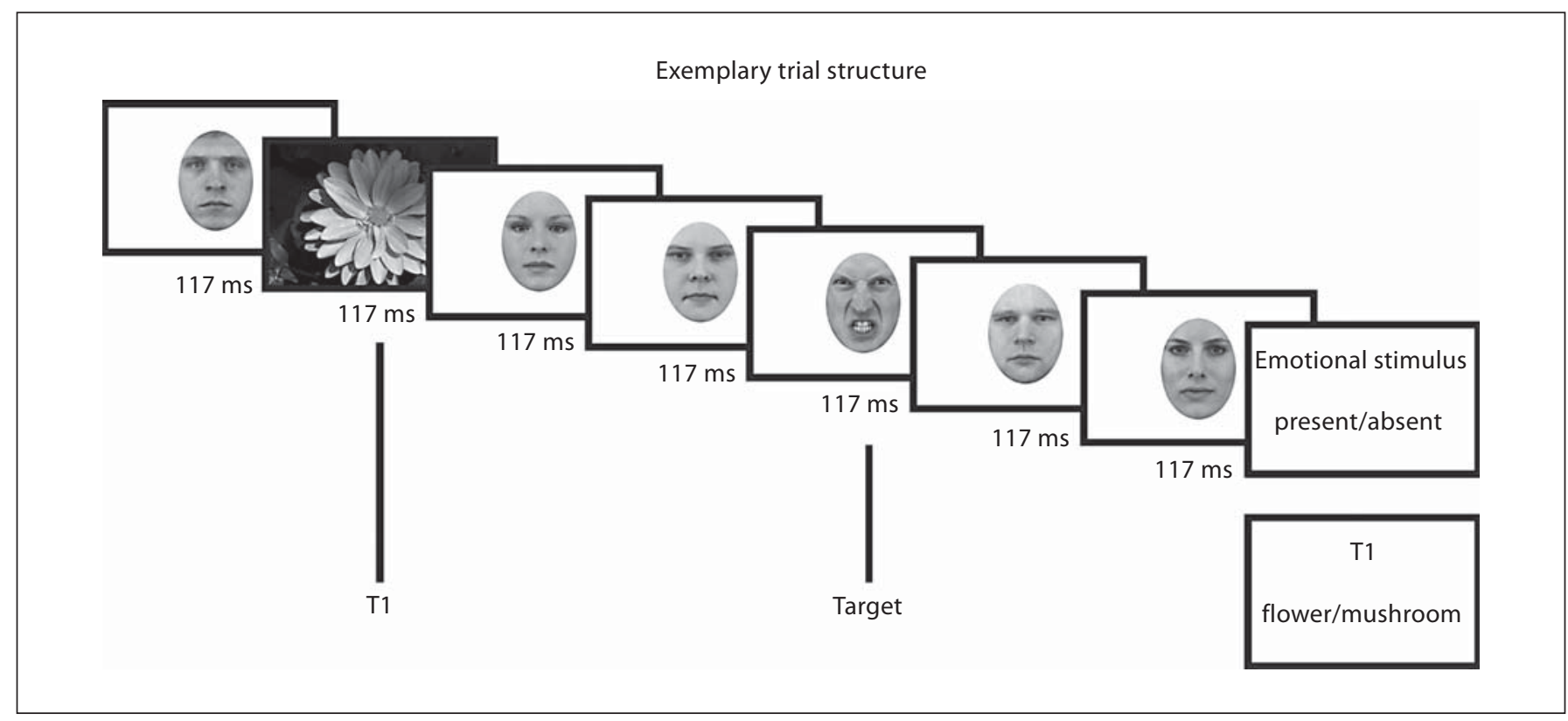

Fig. 1. Participants were presented a rapid stream of 15 stimuli per trial. Each trial contained a picture of flowers or mushrooms (T1) that appeared in positions 2-7 of the trial sequence. Furthermore, some trials contained an emotional (angry or happy) facial stimulus that was presented 2, 3 or 6 stimuli after T1. The remaining stimuli were neutral facial expressions. In single-task trials, the participants had to indicate whether an emotional stimulus was presented in the trial sequence, while ignoring T1. In dual-task trials, they were first asked to report the presence of an emotional stimulus and had then to report whether T1 was a picture of flowers or mushrooms.

trial. During dual-task trials the participants were, again, at first required to report whether an emotional facial expression was presented, but had furthermore to decide if T1 was a picture of flowers or mushrooms. In this way, the availability of cognitive resources was manipulated while assuring constant physical content for both task demands. Finally, we varied the temporal distance between $\mathrm{T} 1$ and emotional facial stimuli to explore whether cognitive processing of $\mathrm{T} 1$ interferes with the recognition of temporally closely presented emotional stimuli [51]. Emotional stimuli were presented 2, 3 or 6 stimuli after T1 (corresponding to a temporal distance of 233, 350 or $700 \mathrm{~ms}$ between T1 and facial expressions of emotions).

To summarize, we manipulated the valence of emotional stimuli (angry and happy), cognitive processing demands (single- and dual-task), and the temporal distance between T1 and facial expressions of emotions (233, 350 or $700 \mathrm{~ms}$ ). The experiment consisted of 216 trials and was divided into 4 blocks ( 2 single-task and 2 dual-task blocks). Prior to each block, an instruction cue was given regarding the task demands in the following trials. A total of 144 trials contained emotional stimuli, while the remaining 72 trials contained only neutral facial expressions.

The experiment was conducted on a standard notebook with a 15 -inch screen and a screen resolution of $800 \times 600$. The presentation of visual stimuli and the collection of behavioral data was realized using Cogent 2000. All the participants underwent a training session to ensure appropriate understanding of the task.
Table 1. Demographic and clinical characteristics of healthy controls and BPD patients

\begin{tabular}{|c|c|c|c|}
\hline & $\mathrm{HC}(\mathrm{n}=25)$ & $\operatorname{BPD}(n=20)$ & $\mathrm{p}$ \\
\hline \multicolumn{4}{|l|}{ Demographics } \\
\hline Age & $26 \pm 6$ & $24 \pm 6$ & 0.132 \\
\hline Intelligence quotient & $122 \pm 14$ & $113 \pm 15$ & 0.040 \\
\hline \multicolumn{4}{|l|}{$\begin{array}{l}\text { Clinical characteristics } \\
\text { BDI }\end{array}$} \\
\hline Depression & $3.28 \pm 4.68$ & $28.35 \pm 10.27$ & $<0.001$ \\
\hline BSI & & & \\
\hline $\begin{array}{l}\text { Global severity } \\
\text { Positive symptom }\end{array}$ & $0.18 \pm 0.17$ & $1.60 \pm 0.67$ & $<0.001$ \\
\hline BSL-23 distress index & $1.17 \pm 0.26$ & $2.29 \pm 0.46$ & $<0.001$ \\
\hline $\begin{array}{l}\text { BPD symptoms } \\
\text { ZAN-BPD }\end{array}$ & $2.28 \pm 3.53$ & $46.65 \pm 23.12$ & $<0.001$ \\
\hline BPD symptoms & & $11.70 \pm 4.92$ & \\
\hline
\end{tabular}

Values are presented as means \pm SD. Group comparisons were conducted using Student's t tests. $\mathrm{HC}=$ Healthy controls; BDI = Beck Depression Inventory; BSI = Brief Symptom Inventory; BSL = Borderline Symptom List; ZAN-BPD = Zanarini Rating Scale for BPD.

Psychopathology 2013;46:217-224 
Fig. 2. Detection of emotional facial expressions as a function of task demands (single- and dual-task demands), valence (angry and happy) and group (BPD patients and healthy controls, HC). Error bars represent standard error of mean.

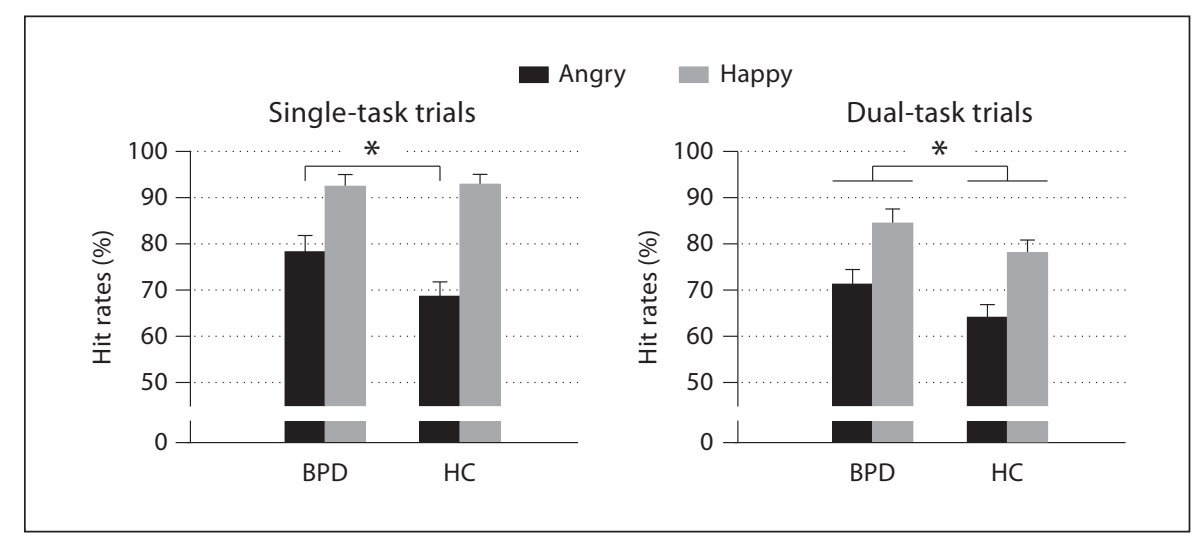

\section{Statistical Analysis}

The correct recognition of emotional stimuli, i.e. hit rates, were analyzed for single- and dual-task trials using separate mixed-design ANOVAs with the following factors, valence (angry and happy), temporal distance $(233,350$ and $700 \mathrm{~ms}$ ) and group (healthy controls and patients with BPD). To investigate the effects of manipulating cognitive resources available for the detection of emotional stimuli (dual-task demands), we only included trials with correct discrimination of T1 [51]. In addition, false alarm rates were analyzed for trials that contained exclusively neutral facial stimuli to determine whether BPD patients show a general response bias to more strongly affirm the presence of emotional stimuli.

Intelligence was used as a covariate in all statistical analyses (see table 1). Greenhouse-Geisser corrections were applied if the assumption of sphericity was violated and significant interactions were followed by simple effects analyses. Analyses were performed using SPSS version 17. The significance level for all tests was $\mathrm{p}<0.05$.

\section{Results}

\section{Single-Task Trials}

Firstly, we analyzed the recognition of emotional stimuli in single-task trials. The results of a repeatedmeasures ANOVA revealed a significant main effect of emotion $\left(F_{1,42}=8.31, p=0.006, \eta_{p}^{2}=0.165\right)$ as healthy controls and patients with BPD showed an enhanced recognition of happy facial stimuli (see fig. 2). Importantly, the results also illustrated an interaction of group by emotion $\left(F_{1,42}=4.26, p=0.045, \eta_{p}^{2}=0.092\right)$. Follow-up analyses of simple effects suggested an enhanced recognition of angry facial stimuli in patients with BPD compared to healthy controls (angry: $\mathrm{F}_{1,42}=4.11, \mathrm{p}=0.049$, $\eta_{\mathrm{p}}^{2}=0.089$; happy: $\left.\mathrm{F}_{1,42}=0.02, \mathrm{p}=0.895, \eta_{\mathrm{p}}^{2}=0.000\right)$. No further significant main effects or interactions of the experimental factors were found (all $\mathrm{p}>0.10$ ).
Statistical analyses of false alarms in single-task trials without emotional stimuli yielded no significant differences between the healthy controls and patients with BPD $\left(\mathrm{F}_{1,42}=2.54, \mathrm{p}=0.118, \eta_{\mathrm{p}}^{2}=0.057\right)$.

\section{Dual-Task Trials}

Following the single-task trials, the correct recognition of emotional facial expressions was analyzed during dual-task demands. As stated in the Methods section, only trials with correct discrimination of $\mathrm{T} 1$ were analyzed to ensure cognitive processing of the respective stimuli in all participants. Despite generally high accuracy scores in both groups (mean \pm SD; BPD: $85.06 \pm$ 9.83; healthy controls: $92.06 \pm 9.78$ ), the patients with $\mathrm{BPD}$ were found to be significantly worse in the discrimination of $\mathrm{T} 1$ compared to the healthy controls $\left(\mathrm{F}_{1,42}=\right.$ $\left.5.39, \mathrm{p}=0.025, \eta_{\mathrm{p}}^{2}=0.114\right)$. The impaired recognition of $\mathrm{T} 1$ in the BPD group was neither modulated by a specific valence nor the temporal distance between T1 and emotional facial expressions (all $\mathrm{p}>0.60$ ). Thus, as only trials with correct classification of T1 were analyzed and the BPD patients were found to be significantly worse in this regard, we included the mean accuracy rate in the discrimination of $\mathrm{T} 1$ as a covariate in the repeated-measures ANOVA.

The statistical analysis of hit rates during dual-task demands showed a significant main effect of group $\left(\mathrm{F}_{1,41}=\right.$ 4.56, $\left.\mathrm{p}=0.039, \eta_{\mathrm{p}}^{2}=0.100\right)$, i.e. the patients with BPD showed a better recognition of emotional facial expressions in general compared to the healthy controls (see fig. 2). No further significant main effects or interactions were found (all $\mathrm{p}>0.25$ ). Again, the BPD patients and healthy controls did not significantly differ in false alarm rates $\left(\mathrm{F}_{1,41}=2.47, \mathrm{p}=0.124, \eta_{\mathrm{p}}^{2}=0.057\right)$. 


\section{Discussion}

The present study investigated whether patients with BPD are characterized by an enhanced detection of emotional facial expressions in a task with rapidly changing facial stimuli. Relative to the healthy controls, the BPD group showed a superior detection of emotional stimuli. In line with previous research that suggested a bias towards the perception of anger [21] as well as a tendency to interpret ambiguous stimuli more negatively in BPD patients [35, 37], we observed a heightened sensitivity for angry facial expressions in single-task trials. During dual-task demands, in contrast, the BPD patients showed an enhanced detection of angry but also of happy facial expressions. This dissociation in the detection of emotional stimuli might be attributable to an observed ceiling effect in the recognition of positive stimuli during single-task trials. Happy facial expressions are generally more easily detected or recognized than angry facial stimuli $[52,53]$, restricting the possibility to detect between-group differences. In our study, both groups showed an almost perfect detection of positive stimuli (>90\%) during singletask conditions. For that reason, we propose our results to reflect a generally enhanced detection of emotional stimuli, which is in line with assumptions of an enhanced sensitivity for emotional stimuli in BPD patients.

It might be questioned whether the superior detection of emotional stimuli reflects a heightened sensitivity in $\mathrm{BPD}$ or is rather the result of a known bias to perceive neutral stimuli (that were predominantly presented in all trials) as more fearful [37] and less friendly [38]. This negativity bias in the evaluation of neutral expressions was also shown to be particularly pronounced when BPD patients were forced to rapidly discriminate emotional states of others [34]. However, analyses of false alarm rates in the present study yielded no significant differences between the two groups, i.e. the BPD patients did not show a significant response bias.

Remarkably, the BPD group also showed a diminished accuracy in the discrimination of T1. Impaired discrimination of $\mathrm{T} 1 \mathrm{might}$ reflect a prioritized attentional orienting towards emotional stimuli in BPD patients that is at the expense of further cognitive processing requirements. Alterations in the distribution of attentional resources, although in the spatial domain, were previously found in BPD patients [54]. In particular, the authors reported that patients with BPD are characterized by an impaired ability to disengage attention from negative facial stimuli. The investigation of attentional processes as well as the role of emotional stimuli with attentional processes might consequently represent a promising avenue to study emotional sensitivity in greater depth.

Although the paradigm is quite different from previous studies on emotional sensitivity in BPD, and theoretical distinctions between facial emotion recognition and emotion detection have to be made, the results seemingly support two isolated findings indicating enhanced emotional sensitivity in patients with BPD [30, 31]. For instance, the results by Fertuck et al. [30] illustrated that BPD patients might be better at mental state discrimination based only on the eye region of individuals. Importantly, the authors observed this effect not only for negative expressions but also for positive ones.

Nevertheless, considering the findings presented in the Introduction, the overwhelming majority of studies in BPD rather point to subtle impairments in the recognition of emotion. Trying to merge this general line of research in emotion recognition with the results presented in this manuscript, we want to carefully propose a mechanism that might help to combine these seemingly contradictory findings, i.e. emotion labeling. Up to now, studies investigating the recognition of emotional states relied exclusively on the use of verbal labels to measure the accuracy of emotion recognition. However, the necessity to label emotions might come into conflict with assessments of a heightened sensitivity in patients with BPD. This proposed confound seems particularly plausible considering the marked differences of BPD patients in the semantic representation of emotional labels compared healthy controls [55], as well as their pronounced difficulties in using emotional labels to describe their own emotional states $[11,56]$. Recent work further supported this argument by illustrating that difficulties in the ability of BPD patients to identify and label emotional states are indeed a significant predictor for the performance in emotion recognition tasks [57]. In contrast, the participants in our study were only asked to indicate the presence of an emotional stimulus without the need to label the emotional state. Quite similarly, a recent study without labeling requirements found stronger initial attentional orienting of BPD patients to emotional stimuli, which suggests an enhanced sensitivity towards emotional information in BPD [40]. Consequently, we do suggest that BPD patients might be characterized by an enhanced detection of emotional expressions by others, while also showing difficulties in accurately describing the depicted emotions at the same time. Intriguingly, the labeling of emotions was found to attenuate self-reported emotional experiences [58] and to diminish limbic activity [59]. Impairments in the labeling of emotional responses might 
thus contribute to emotional instability in patients with BPD.

Accordingly, our results are proposed to be consistent with the emotional instability phenotype as a central feature of BPD. In addition, enhanced detection of emotional expressions in the faces of others may also be related to the interpersonal hypersensitivity phenotype [60]. Our results may reflect that BPD patients are hypersensitive to emotional states perceived in other's faces as they have learnt to expose high attention to the emotional states of others in an unpredictable or even threatening environment. Our paradigm does not allow for differentiating between emotional and interpersonal hypersensitivity in patients with BPD, which might anyhow strongly interact in the social context.

The present study has some limitations that need to be acknowledged and might be addressed in future studies to broaden the understanding of emotional sensitivity in BPD patients. First, we proposed the superior detection of emotional stimuli in the BPD group to be related to the response format as the participants were not required to indicate the specific valence. Although this interpretation seems plausible regarding the current state of research in BPD, the experimental paradigm chosen did not allow for directly comparing accuracy scores with and without the need to label the specific emotional state. Thus, further research is needed to determine whether BPD patients show an initially heightened detection of emotional facial expressions but are characterized by impairments in the subsequent labeling of these emotional states. In addition, future research is needed to investi- gate the specificity of these results for BPD (e.g. by including a psychopathological control group) and whether the presented results are also applicable to male patients with BPD. Third, while the temporal distance between T1 and the presented emotional stimuli was experimentally manipulated, there was no significant evidence for a decline in performance accuracy when $\mathrm{T} 1$ and emotional stimuli were presented in close temporal succession [54].

The results of this study demonstrate an enhanced emotional sensitivity - in the sense of a superior detection of emotional stimuli - in patients with BPD. More specifically, we argued that a higher detection of emotional information along with deficits in the labeling of emotions might contribute to the characteristic pattern of emotional instability. In addition, the superior detection of emotional stimuli during dual-task demands was found to be at the expense of further cognitive processing requirements.

\section{Acknowledgements}

We are grateful to Refa-Maria Jacobs and Kristin Mildner for their support in the collection of the data and we also thank Inga Niedtfeld for valuable comments on a previous version of the manuscript.

\section{Disclosure Statement}

Sabine C. Herpertz is an editor of Psychopathology but had no part in the evaluation of this paper for publication.

\section{References}

1 Lenzenweger MF, Lane MC, Loranger AW, Kessler RC: DSM-IV personality disorders in the National Comorbidity Survey Replication. Biol Psychiatry 2007;62:553-564.

-2 Grant BF, Chou SP, Goldstein RB, Huang B, Stinson FS, Saha TD, Smith SM, Dawson DA, Pulay AJ, Pickering RP, Ruan WJ: Prevalence, correlates, disability, and comorbidity of DSM-IV borderline personality disorder: results from the Wave 2 National Epidemiologic Survey on Alcohol and Related Conditions. J Clin Psychiatry 2008;69:533545.

-3 Glenn CR, Klonsky ED: Emotion dysregulation as a core feature of borderline personality disorder. J Pers Disord 2009;23: $20-28$.
4 Trull TJ, Solhan MB, Tragesser SL, Jahng S, Wood PK, Piasecki TM, Watson D: Affective instability: measuring a core feature of borderline personality disorder with ecological momentary assessment. J Abnorm Psychol 2008;117:647-661.

5 McGlashan TH, Grilo CM, Sanislow CA, Ralevski E, Morey LC, Gunderson JG, Skodol AE, Shea MT, Zanarini MC, Bender D, Stout RL, Yen S, Pagano M: Two-year prevalence and stability of individual DSM-IV criteria for schizotypal, borderline, avoidant, and obsessive-compulsive personality disorders: toward a hybrid model of axis II disorders. Am J Psychiatry 2005;162:883-889.

-6 Stiglmayr CE, Grathwol T, Linehan MM, Ihorst G, Fahrenberg J, Bohus M: Aversive tension in patients with borderline personality disorder: a computer-based controlled field study. Acta Psychiatr Scand 2005;111:372-379.
7 Klonsky ED: The functions of deliberate selfinjury: a review of the evidence. Clin Psychol Rev 2007;27:226-239.

-8 Chapman AL, Gratz KL, Brown MZ: Solving the puzzle of deliberate self-harm: the experiential avoidance model. Behav Res Ther 2006;44:371-394.

-9 Koenigsberg HW, Harvey PD, Mitropoulou V, New AS, Goodman M, Silverman J, Serby M, Schopick F, Siever LJ: Are the interpersonal and identity disturbances in the borderline personality disorder criteria linked to the traits of affective instability and impulsivity? J Pers Disord 2001;15: 358-370.

10 Tragesser SL, Solhan M, Schwartz-Mette R, Trull TJ: The role of affective instability and impulsivity in predicting future BPD features. J Pers Disord 2007;21:603-614. 
11 Linehan MM: Cognitive-Behavioral Treatment for Borderline Personality Disorder. New York, Guilford Press, 1993.

-12 Herpertz SC, Dietrich TM, Wenning B, Krings T, Erberich SG, Willmes K, Thron A, Sass H: Evidence of abnormal amygdala functioning in borderline personality disorder: a functional MRI study. Biol Psychiatry 2001;50:292-298.

-13 Prehn K, Schulze L, Rossmann S, Berger C, Vohs K, Fleischer M, Hauenstein K, Keiper P, Domes G, Herpertz S: Effects of emotional stimuli on working memory processes in male criminal offenders with borderline and antisocial personality disorder. World J Biol Psychiatry, E-pub ahead of print.

-14 Donegan NH, Sanislow CA, Blumberg HP, Fulbright RK, Lacadie C, Skudlarski P, Gore JC, Olson IR, McGlashan TH, Wexler BE: Amygdala hyperreactivity in borderline personality disorder: implications for emotional dysregulation. Biol Psychiatry 2003;54 1284-1293.

15 Minzenberg MJ, Fan J, New AS, Tang CY, Siever LJ: Fronto-limbic dysfunction in response to facial emotion in borderline personality disorder: an event-related fMRI study. Psychiatry Res 2007;155:231-243.

-16 Niedtfeld I, Schulze L, Kirsch P, Herpertz SC, Bohus M, Schmahl C: Affect regulation and pain in borderline personality disorder: a possible link to the understanding of self-injury. Biol Psychiatry 2010;68:383-391.

-17 Koenigsberg HW, Fan J, Ochsner KN, Liu X, Guise KG, Pizzarello S, Dorantes C, Guerreri S, Tecuta L, Goodman M, New A, Siever LJ: Neural correlates of the use of psychological distancing to regulate responses to negative social cues: a study of patients with borderline personality disorder. Biol Psychiatry 2009;66:854-863.

- 18 Schulze L, Domes G, Kruger A, Berger C, Fleischer M, Prehn K, Schmahl C, Grossmann A, Hauenstein K, Herpertz SC: Neuronal correlates of cognitive reappraisal in borderline patients with affective instability. Biol Psychiatry 2011;69:564-573.

$\checkmark 19$ Frank H, Hoffman N: Borderline empathy an empirical investigation. Compr Psychiatry 1986;27:387-395.

20 Krohn A: Borderline empathy and differentiation of object representations - contribution to psychology of object relations. Int J Psychoanal Psychother 1974;3:142-165.

-21 Domes G, Czieschnek D, Weidler F, Berger C, Fast K, Herpertz SC: Recognition of facial affect in borderline personality disorder. J Pers Disord 2008;22:135-147.

22 Franzen N, Hagenhoff M, Baer N, Schmidt A, Mier D, Sammer G, Gallhofer B, Kirsch P, Lis S: Superior 'theory of mind' in borderline personality disorder: an analysis of interaction behavior in a virtual trust game. Psychiatry Res 2011;187:224-233.
23 Gardner KJ, Qualter P, Tremblay R: Emotional functioning of individuals with borderline personality traits in a nonclinical population. Psychiatry Res 2010;176:208212.

24 Bland AR, Williams CA, Scharer K, Manning $S$ : Emotion processing in borderline personality disorders. Issues Ment Health Nurs 2004;25:655-672.

25 Levine D, Marziali E, Hood J: Emotion processing in borderline personality disorders. Nerv Ment Dis 1997;185:240-246.

26 Unoka Z, Fogd D, Fuzy M, Csukly G: Misreading the facial signs: specific impairments and error patterns in recognition of facial emotions with negative valence in borderline personality disorder. Psychiatry Res 2011;189:419-425.

27 Ritter K, Dziobek I, Preissler S, Ruter A, Vater A, Fydrich T, Lammers CH, Heekeren HR, Roepke S: Lack of empathy in patients with narcissistic personality disorder. Psychiatry Res 2011;187:241-247.

28 Preissler S, Dziobek I, Ritter K, Heekeren HR, Roepke S: Social cognition in borderline personality disorder: evidence for disturbed recognition of the emotions, thoughts, and intentions of others. Front Behav Neurosci 2010;4:182.

29 Merkl A, Ammelburg N, Aust S, Roepke S, Reinecker H, Trahms L, Heuser I, Sander T: Processing of visual stimuli in borderline personality disorder: a combined behavioural and magnetoencephalographic study. Int J Psychophysiol 2010;78:257-264.

30 Fertuck EA, Jekal A, Song I, Wyman B, Morris MC, Wilson ST, Brodsky BS, Stanley B Enhanced 'reading the mind in the eyes' in borderline personality disorder compared to healthy controls. Psychol Med 2009;39: 1979-1988.

31 Lynch TR, Rosenthal MZ, Kosson DS, Cheavens JS, Lejuez CW, Blair RJ: Heightened sensitivity to facial expressions of emotion in borderline personality disorder. Emotion 2006;6:647-655.

32 Schilling L, Wingenfeld K, Lowe B, Moritz S, Terfehr K, Kother U, Spitzer C: Normal mind-reading capacity but higher response confidence in borderline personality disorder patients. Psychiatry Clin Neurosci 2012; 66:322-327.

33 Minzenberg MJ, Poole JH, Vinogradov S: Social-emotion recognition in borderline personality disorder. Compr Psychiatry 2006; 47:468-474.

34 Dyck M, Habel U, Slodczyk J, Schlummer J, Backes V, Schneider F, Reske M: Negative bias in fast emotion discrimination in borderline personality disorder. Psychol Med 2009;39:855-864.

35 Arntz A, Veen G: Evaluations of others by borderline patients. J Nerv Ment Dis 2001; 189:513-521.
6 Barnow S, Stopsack M, Grabe HJ, Meinke C, Spitzer C, Kronmuller K, Sieswerda S: Interpersonal evaluation bias in borderline personality disorder. Behav Res Ther 2009;47: 359-365

37 Wagner AW, Linehan MM: Facial expression recognition ability among women with borderline personality disorder: implications for emotion regulation? J Pers Disord 1999; 13:329-344.

38 Meyer B, Pilkonis PA, Beevers CG: What's in a (neutral) face? Personality disorders, attachment styles, and the appraisal of ambiguous social cues. J Pers Disord 2004;18:320336.

39 Domes G, Schulze L, Herpertz SC: Emotion recognition in borderline personality disorder - a review of the literature. J Pers Disord 2009;23:6-19.

40 von Ceumern-Lindenstjerna IA, Brunner R, Parzer P, Mundt C, Fiedler P, Resch F: Initial orienting to emotional faces in female adolescents with borderline personality disorder. Psychopathology 2010;43:79-87.

41 Mathews A, MacLeod C: Cognitive vulnerability to emotional disorders. Annu Rev Clin Psychol 2005;1:167-195.

42 MacLeod C, Rutherford E, Campbell L, Ebsworthy G, Holker L: Selective attention and emotional vulnerability: assessing the causal basis of their association through the experimental manipulation of attentional bias. J Abnorm Psychol 2002;111:107-123.

43 Hall JA, Matsumoto D: Gender differences in judgments of multiple emotions from facial expressions. Emotion 2004;4:201-206.

44 Skodol AE, Bender DS: Why are women diagnosed borderline more than men? Psychiatr Q 2003;74:349-360.

45 Loranger AW, Susman VL, Oldham HM, Russakoff LM: International personality disorder examination (IPDE): A Structural Interview for DSM-IV and ICD-10 Personality Disorders. White Plains, New York Hospital Cornell Medical Center, Westchester Division, 1996.

46 Zanarini MC, Vujanovic AA, Parachini EA, Boulanger JL, Frankenburg FR, Hennen J: Zanarini Rating Scale for Borderline Personality Disorder (ZAN-BPD): a continuous measure of DSM-IV borderline psychopathology. J Pers Disord 2003;17:233-242.

47 Bohus M, Kleindienst N, Limberger MF, Stieglitz RD, Domsalla M, Chapman AL, Steil R, Philipsen A, Wolf M: The short version of the Borderline Symptom List (BSL23): development and initial data on psychometric properties. Psychopathology 2009;42: 32-39.

48 Franke GH: SCL-90-R: The Symptom Checklist of Derogatis - German Version. Weinheim, Beltz, 1995.

49 Beck AT, Hautzinger M, Bailer M, Worall H, Keller F: Beck Depressions-Inventar (BDI). Göttingen, Hogrefe, 1995. 
50 Lundqvist D, Flykt A, Öhman A: The Karolinska Directed Emotional Faces - KDEF (CD-ROM). Solna, Department of Clinical Neuroscience, Psychology Section, Karolinska Institute, 1998.

51 Fox E, Russo R, Georgiou GA: Anxiety modulates the degree of attentive resources required to process emotional faces. Cogn Affect Behav Neurosci 2005;5:396-404.

52 Esteves F, Ohman A: Masking the face: recognition of emotional facial expressions as a function of the parameters of backward masking. Scand J Psychol 1993;34:1-18.

53 Schulze L, Lischke A, Greif J, Herpertz SC, Heinrichs M, Domes G: Oxytocin increases recognition of masked emotional faces. Psychoneuroendocrinology 2011;36:1378-1382.
54 von Ceumern-Lindenstjerna IA, Brunner R, Parzer P, Mundt C, Fiedler P, Resch F: Attentional bias in later stages of emotional information processing in female adolescents with borderline personality disorder. Psychopathology 2010;43:25-32.

55 Suvak MK, Litz BT, Sloan DM, Zanarini MC, Barrett LF, Hofmann SG: Emotional granularity and borderline personality disorder. J Abnorm Psychol 2011;120:414-426.

56 Wolff S, Stiglmayr C, Bretz HJ, Lammers $\mathrm{CH}$, Auckenthaler A: Emotion identification and tension in female patients with borderline personality disorder. Br J Clin Psychol 2007;46:347-360.
Domes G, Grabe HJ, Czieschnek D, Heinrichs M, Herpertz SC: Alexithymic traits and facial emotion recognition in borderline personality disorder. Psychother Psychosom 2012;80:383-385.

58 Lieberman MD, Inagaki TK, Tabibnia G, Crockett MJ: Subjective responses to emotional stimuli during labeling, reappraisal, and distraction. Emotion 2011;11:468-480.

59 Lieberman MD, Eisenberger NI, Crockett MJ, Tom SM, Pfeifer JH, Way BM: Putting feelings into words - affect labeling disrupts amygdala activity in response to affective stimuli. Psychol Sci 2007;18:421-428.

60 Gunderson JG, Lyons-Ruth K: BPD's interpersonal hypersensitivity phenotype: a geneenvironment developmental model. J Pers Disord 2008;22:22-41. 